\title{
Reproducibility of fingerprint microfeatures
}

\author{
Jaisleen Kaur and Meenal Dhall*
}

\begin{abstract}
Background: Poroscopy, as a means of personal identification, is largely unexplored. The present study aims at assessing the reproducibility of fingerprint microfeatures namely, pore area, inter-distance, and angle, in fingerprints obtained on two surfaces namely, glass and sticky side of adhesive tape, for a period of ten consecutive days. As far as the authors are aware, no prior research has attempted to evaluate pore parameters on sticky side of adhesive tape.

Methods: Plain-inked fingerprints of the left thumb, right thumb, and right index finger were collected on two surfaces namely, glass and sticky side of adhesive tape (using two methods) for ten consecutive days. Photomicrographs were captured and four pores, lying on the same ridge and having clear well-defined margins, were selected from the central region of each print. These specific sweat pores were used to measure the pore area, inter-distance, and angle using Image Pro ${ }^{\circledR}$ Software. Data were analyzed using Statistical Product and Service Solutions (SPSS) software version 16. One way analysis of variance (ANOVA) was carried out using "area," "length," and "angle" as the dependent variables.

Results: Results obtained depict pore area, inter-distance, and angle to be significant $(p<0.001)$, on all 10 days for both the surfaces. In terms of quality, better pore details were depicted by fingerprints obtained on the sticky side of adhesive tape (using procedure (iii), wherein the sticky side of adhesive tape was pressed against the inked thumb of the participant). Furthermore, the pore area was found to be non-reproducible while the pore inter-distance and angle were found to be reliable and reproducible in nature.
\end{abstract}

Conclusions: Crime scene fingerprints should be first matched with specimen fingerprints on the basis of ridge characteristics. However, on occasions when sufficient number of ridge characteristics are not available for comparison, sweat pores should be employed. This study highlights the reproducibility and reliability of pore inter-distance and angle and encourages their use in fingerprint matching.

Keywords: Poroscopy, Sweat pores, Fingerprint microfeatures, Pore area, Pore inter-distance, Pore angle, Sticky side of adhesive tape

\section{Background}

Fingerprints have great discriminatory power and are one of the most important and commonly encountered evidences at the scene of crime (SOC) (Thakar and Sharma 2016; Vij 2001). Due to their unique, immutable, and classifiable nature, fingerprints have been universally accepted as a means of personal identification since centuries. The questioned and specimen fingerprints are matched at three levels (Anthonioz et al. 2011; Ashbaugh 1999; Ashbaugh and Houck 2005; Jain et al. 2006; Liu

\footnotetext{
*Correspondence: say2meenal@gmail.com
}

Department of Anthropology, University of Delhi, Delhi 110007, India et al. 2020; Maltoni et al. 2009; Pankanti et al. 2002; Stosz and Alyea 1994). The first level of fingerprint matching deals with macrofeatures (Jain et al. 2006), i.e., pattern type, ridge count, core, delta, and orientation. Level two consists of matching the relative nature and position of ridge characteristics (Galton's minutiae) (Labati et al. 2018; Preethi et al. 2012). Level three involves the use of intra-ridge details (Kryszczuk et al. 2004) or microfeatures (Ashbaugh 1999; Gupta et al. 2008) such as sweat pores, edge contours, friction ridge width, dots, incipient ridges, creases, and scars (Ashbaugh and Houck 2005; Jain et al. 2006).

Fingerprints retrieved from the SOC can be complete or partial (fragmented). In case of the former, 
identification process, i.e., analysis-comparison-evaluation and verification (ACE-V), is relatively simple to conduct. However, the latter poses many problems mainly due to insufficient landmarks or level two details, unspecified orientation, and non-linear distortion (Gupta and Sutton 2010). Moreover, the print may be deposited from any other part of the hand than the finger tips (Ashbaugh 1999). Poroscopy, the specialized study of sweat pores found on the papillary ridges of the skin, can be especially useful in such cases (Ashbaugh and Houck 2005; Bindra et al. 2000; Cai et al. 2017; Gupta and Sutton 2010; Lee et al. 2014; Nagesh et al. 2011; Oklevski 2011; Park et al. 2016; Zhao et al. 2010a, 2010b).

The science of poroscopy was developed by Dr. Edmond Locard of Lyon, France, in 1912 (Ashbaugh 1999). Locard stated that like ridge characteristics, pores are permanent, immutable, and unique in nature and can aid in identification. He further proposed that 20-40 sweat pores in agreement are mathematically sufficient to prove the identity (Ashbaugh 1999). Sweat pores can be analyzed on the basis of the following features namely, number (per unit area and per unit length), shape, size, position (middle or periphery), type (closed, open on the one end, and open on both ends), and inter-distance.

The use of pore-to-pore distance for individualizing fingerprints has been effectively suggested by many studies (Anthonioz et al. 2011; Ashbaugh 1999; Liu et al. 2020; Monson et al. 2019; Oklevski 2011; Oktem et al. 2015; Parsons et al. 2008). However, no study has demonstrated the same using empirical data. When a pore undergoes distortion (due to pressure), it stretches (owing to the elasticity and compression of the skin), which results in change in its shape, size, and type (closed, open on the one side, and open on both sides). However, the inter-distance remains more or less the same. This is because the distance between pores is very minute (in $\mu \mathrm{m}$ ); thus, multiple pores, on the same or different ridge(s), will be influenced simultaneously. Hence, pore inter-distance, with respect to each other, i.e., from the center of one pore to the center of the adjacent pore will remain more or less the same (within acceptable reproducible limits, i.e., with $5 \%$ confidence level in analytical work) for every individual. This forms the hypothesis of the present study.

In the present research work, an attempt has been made to study the reproducibility of two pore attributes namely, area and inter-distance (angle has also been taken into consideration), in fingerprints recorded over a period of ten consecutive days on two surfaces, i.e., glass and sticky side of adhesive tape, due to their increased use in day-to-day life. Moreover, the authors wanted to observe pore details on one porous and non-porous surface each hence, glass (non-porous) and sticky side of adhesive tape (porous) were selected. As far as we are aware, no prior research has attempted to evaluate pore parameters on the sticky side of adhesive tape.

\section{Methods}

Plain prints of the left thumb, right thumb, and right index finger were considered for the study as these are the most commonly used digits and thus will almost always leave fingerprints on the surface/object with which they come in contact. Both the thumbs were considered because thumb imprints are of utmost importance and are often used as signature, biometrics, etc. (Kapoor and Badiye 2015). A thin layer of black printer's ink was spread uniformly on a glass slab (12 x 7.5 inch), using a rubber roller (the ink was spread so thin that light could pass through it). A total of 120 fingerprints were collected from four adult individuals (1 female and 3 males), selected at random (participants with any evidence of disease and/or injury to finger tips were excluded). Informed written consent was obtained, and the participants were asked to wash and dry their hands thoroughly before recording their fingerprints.

Plain inked fingerprints were collected in the following manner: (i) left thumb-the participant was asked to place his/her left thumb onto the ink-smeared glass slab, with medium pressure (judged qualitatively), so that ink coats just the ridges and does not enter the pores, following which the print was deposited on a clean glass slide. Fingerprint thus obtained was left to dry for $5 \mathrm{~min}$ after which the glass slide, bearing the fingerprint, was carefully covered with a transparent tape (2-in-wide) in order to obtain a permanent record. (ii) Right index fingerthe same inking procedure was carried out for the right index finger as well; however, instead of using glass slides, sticky side of clear tape (2-inch-wide) was used as the substrate, i.e., the fingerprint was deposited on adhesive tape, spread on a flat surface, with its sticky side facing upwards. (iii) Right thumb-the same inking procedure (as that in (i) and (ii)) was used followed by pressing the sticky side of tape against the right thumb of the participant, with minimal pressure, in order to obtain the print on it. For both (ii) and (iii), the tape (containing the print) was preserved by adhering it to a transparency sheet $(2.75 \times 1.75 \mathrm{in})$. The above procedure was repeated at the same time of the day, for ten consecutive days (a total of 120 fingerprints were collected and analyzed). All prints were labeled and stored.

Photomicrographs were captured at $\times 40$ magnification using Zeiss Primo Star microscope attached with Canon PowerShot G10 camera (Automode) using a 
SOLIGOR Adaptor tube for Canon 10 (52-mm wide). Four pores each, lying on the same ridge, having clear and well-defined margins, were selected from the central region of each print. Only these specific pores were used throughout the study in order to measure the pore area, inter-distance, and angle, using Image Pro ${ }^{\circledR}$ Software. Photomicrographs were first calibrated using a reference marker (stage micrometer 1-mm scale, Erma, Tokyo) and the "spatial calibration" option in Image Pro ${ }^{\circledR}$ Software.

For measuring the pore area, method used by Gupta et al. (2007) was employed wherein a "best fit" circle touching at least three sides of the pore was drawn. For measuring the pore-to-pore distance, a line joining the center of one pore to the center of the next pore was drawn using the "distance between centers" tool under the "relative" option. Angles were measured using the "angle between lines" tool under the "relative" option. To determine the precision of the measurement method

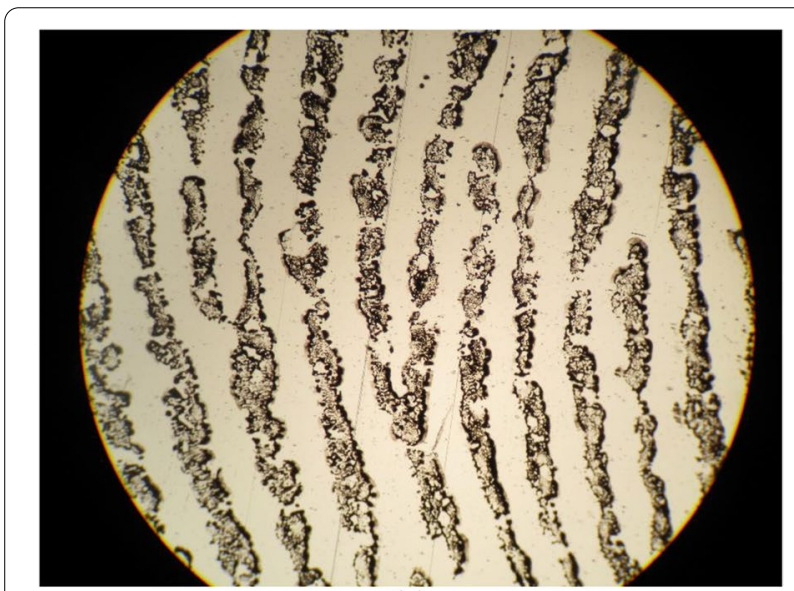

(a)

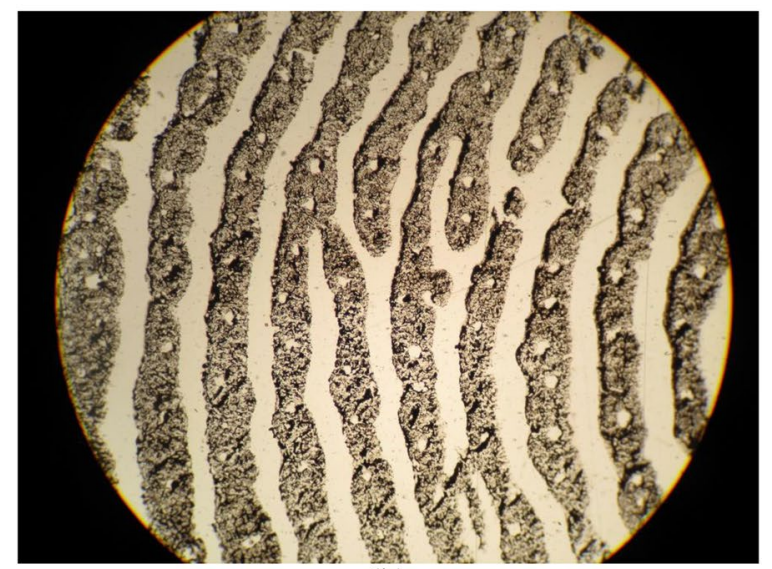

(b)

Fig. 1 Photomicrographs of fingerprint recorded on $\mathbf{a}$ glass and $\mathbf{b}$ sticky side of adhesive tape, captured at $\times 40$ magnification using Zeiss Primo Star microscope attached with Canon PowerShot G10 camera (Automode) using a SOLIGOR Adaptor tube for Canon 10 (52 mm wide) employed and counter intra-observer variability, every reading, i.e., area, inter-distance, and angle, for each pore, was taken ten times.

The reproducibility of two pore attributes, i.e., pore area and pore inter-distance was studied for a period of 10 days. Moreover, the angle between lengths was also observed. The reliability of glass and sticky side of tape as substrates for studying pore details was also examined. Data were analyzed using Statistical Product and Service Solutions (SPSS) software version 16. One-way analysis of variance (ANOVA) was applied using "area," "length," and "angle" as the dependent variables.

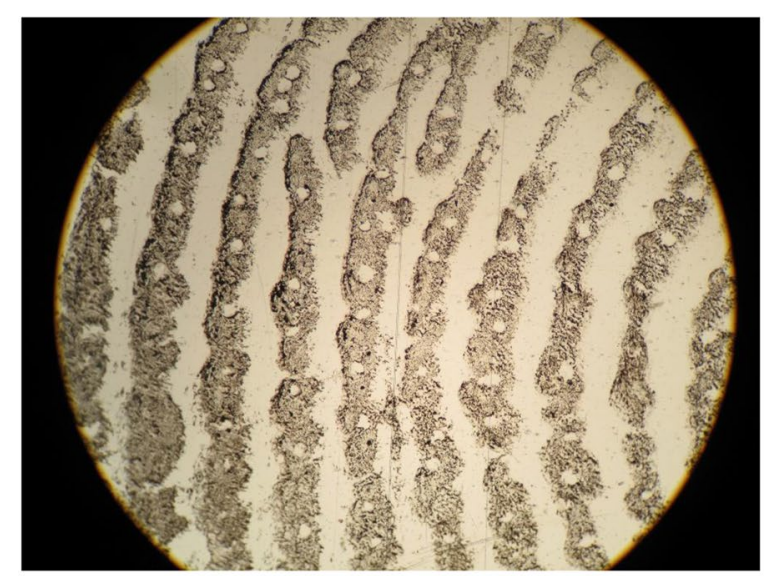

(a)

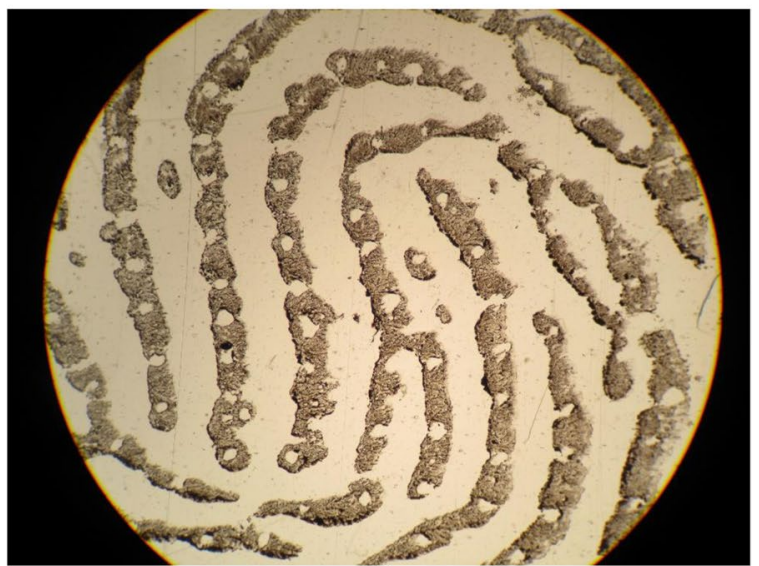

(b)

Fig. 2 Photomicrographs of fingerprint recorded on the sticky side of adhesive tape $\mathbf{a}$ using method (ii) and $\mathbf{b}$ using method (iii), captured at $\times 40$ magnification using Zeiss Primo Star microscope attached with Canon PowerShot G10 camera (Automode) using a SOLIGOR Adaptor tube for Canon 10 (52-mm wide). Fingerprint (b), recorded using method (iii), is better in terms of clarity of ridge and pore margins, sharpness of pore details, and less smudging of ink 


\section{Results}

In terms of quality, out of the two surfaces, i.e., glass and sticky side of adhesive tape, better pore details were visible in prints obtained on the sticky side of adhesive tape (Fig. 1). Furthermore, out of the two methods for recording fingerprints on the sticky side of tape, i.e., (ii) and (iii) (as described under the "Materials and Methods" section), the procedure (iii) gave slightly better-quality prints (in terms of clarity of ridge and pore margins, sharpness of pore details, and less smudging of ink), as can be observed in Fig. 2.

\section{Area}

The size of pores was not found to be reproducible as coefficient of variation (\% C.V.) was beyond the normal acceptable level (with 5\% confidence level in analytical work) for pores recorded over a period of ten consecutive days. Tables 1,2 , and 3 clearly depict the mean area (in $\mu \mathrm{m}^{2}$ ), standard deviation (S. D.), and \% C. V. for the left thumb, right index, and right thumb, of four individuals taken on glass and sticky side of adhesive tape.

Moreover, the pore area was found to be significant $(p<0.001)$ on ten consecutive days, for sweat pores of all four participants, on both the surfaces (using all three

Table 1 Mean area, standard deviation (S. D.), and \% coefficient of variation (\% C.V.) of four pores, taken from fingerprints obtained from the left thumb of four individuals on glass, recorded on ten consecutive days, show \% C. V. to be beyond the normal acceptable level (with 5\% confidence level in analytical work), thereby demonstrating that pore area is not a reproducible feature for matching fingerprints

\begin{tabular}{lllll}
\hline Pore & & Mean area $\left(\boldsymbol{\mu m}^{2}\right)$ & S. D. & \% C. V. \\
\hline Individual 1 & Pore 1 & 8693.00 & 4153.93 & 47.78 \\
& Pore 2 & 5622.57 & 2708.89 & 48.18 \\
& Pore 3 & 6249.84 & 3724.90 & 59.60 \\
& Pore 4 & 2325.52 & 1810.10 & 77.84 \\
Individual 2 & Pore 1 & 10414.51 & 5041.71 & 48.41 \\
& Pore 2 & 11558.77 & 3697.71 & 31.99 \\
& Pore 3 & 9512.30 & 4919.25 & 51.71 \\
Individual 3 & Pore 4 & 6235.20 & 4779.94 & 76.66 \\
& Pore 1 & 14472.17 & 6724.79 & 46.47 \\
& Pore 2 & 13626.06 & 7352.19 & 53.96 \\
& Pore 3 & 10455.74 & 4306.36 & 41.19 \\
& Pore 4 & 6852.05 & 6062.52 & 88.48 \\
Individual 4 & Pore 1 & 15944.53 & 8125.33 & 50.96 \\
& Pore 2 & 13277.69 & 7301.54 & 54.99 \\
& Pore 3 & 13472.14 & 8225.55 & 61.06 \\
& Pore 4 & 13874.03 & 6822.22 & 49.17 \\
\hline
\end{tabular}

Table 2 Mean area, standard deviation (S. D.), and \% coefficient of variation (\% C.V.) of four pores, taken from fingerprints obtained from the right index finger of four individuals on sticky side of adhesive tape (using method (ii)), recorded on ten consecutive days, show \% C. V. to be beyond the normal acceptable level (with 5\% confidence level in analytical work), thereby demonstrating that pore area is not a reproducible feature for matching fingerprints

\begin{tabular}{lllll}
\hline Pore & & Mean area $\left(\boldsymbol{\mu m}^{2}\right)$ & S. D. & \% C. V. \\
\hline Individual 1 & Pore 1 & 11505.31 & 6446.67 & 56.03 \\
& Pore 2 & 10051.27 & 4162.94 & 41.42 \\
& Pore 3 & 12664.45 & 4887.05 & 38.59 \\
& Pore 4 & 9144.70 & 5016.89 & 54.86 \\
Individual 2 & Pore 1 & 12725.86 & 5813.81 & 45.69 \\
& Pore 2 & 8686.24 & 3673.15 & 42.29 \\
& Pore 3 & 6112.12 & 3937.49 & 64.42 \\
& Pore 4 & 9261.24 & 2274.28 & 24.56 \\
Individual 3 & Pore 1 & 10647.77 & 6969.79 & 65.46 \\
& Pore 2 & 7615.40 & 4021.08 & 52.80 \\
& Pore 3 & 6960.05 & 3695.33 & 53.09 \\
& Pore 4 & 8363.05 & 5064.20 & 60.55 \\
Individual 4 & Pore 1 & 8105.30 & 3300.42 & 40.72 \\
& Pore 2 & 14496.30 & 4675.76 & 32.25 \\
& Pore 3 & 11191.14 & 5881.19 & 52.55 \\
& Pore 4 & 7589.88 & 3472.85 & 45.76 \\
\hline
\end{tabular}

Table 3 Mean area, standard deviation (S. D.), and \% coefficient of variation (\% C.V.) of four pores, taken from fingerprints obtained from the right thumb of four individuals on sticky side of adhesive tape (using method (iii)), recorded on ten consecutive days, show \% C. V. to be beyond the normal acceptable level (with 5\% confidence level in analytical work), thereby demonstrating that pore area is not a reproducible feature for matching fingerprints

\begin{tabular}{lllll}
\hline Pore & & Mean area $\left(\boldsymbol{\mu m}^{2}\right)$ & S. D. & \% C. V. \\
\hline Individual 1 & Pore 1 & 7147.79 & 3557.90 & 49.78 \\
& Pore 2 & 8238.88 & 7253.25 & 88.04 \\
& Pore 3 & 6927.15 & 5356.63 & 77.33 \\
& Pore 4 & 8003.17 & 4933.09 & 61.64 \\
Individual 2 & Pore 1 & 3167.00 & 2218.28 & 70.04 \\
& Pore 2 & 3103.47 & 2010.96 & 64.80 \\
& Pore 3 & 3485.84 & 2384.84 & 68.42 \\
Individual 3 & Pore 4 & 4130.92 & 2794.50 & 67.65 \\
& Pore 1 & 7618.72 & 3462.63 & 45.45 \\
& Pore 2 & 6025.12 & 3419.02 & 56.75 \\
& Pore 3 & 3928.39 & 1744.53 & 44.41 \\
& Pore 4 & 12262.17 & 9959.26 & 81.22 \\
Individual 4 & Pore 1 & 10621.20 & 7576.13 & 71.33 \\
& Pore 2 & 6298.58 & 3936.31 & 62.50 \\
& Pore 3 & 6909.11 & 4327.40 & 62.63 \\
& Pore 4 & 6990.86 & 3262.38 & 46.67 \\
\hline
\end{tabular}


Table 4 Results obtained using ANOVA for fingerprints obtained from the left thumb of individual 1 on glass with "area" as the "dependent variable"

\begin{tabular}{|c|c|c|c|c|c|c|}
\hline \multicolumn{7}{|l|}{ ANOVA } \\
\hline & & Sum of Squares & df & Mean Square & $F$ & Sig. \\
\hline \multirow[t]{3}{*}{ Individual1GlassP1AREA } & Between groups & $1.553 \mathrm{e} 9$ & 9 & $1.726 \mathrm{E} 8$ & $1.918 \mathrm{E} 7$ & .000 \\
\hline & Within groups & 809.602 & 90 & 8.996 & & \\
\hline & Total & $1.553 \mathrm{E} 9$ & 99 & & & \\
\hline \multirow[t]{3}{*}{ Individual1GlassP2AREA } & Between groups & $6.604 e 8$ & 9 & 7.338E7 & $6.803 \mathrm{E} 6$ & .000 \\
\hline & Within groups & 970.815 & 90 & 10.787 & & \\
\hline & Total & $6.604 \mathrm{E} 8$ & 99 & & & \\
\hline \multirow[t]{3}{*}{ Individual1GlassP3AREA } & Between groups & $1.249 \mathrm{e} 9$ & 9 & 1.387E8 & $1.149 \mathrm{E} 7$ & .000 \\
\hline & Within groups & 1087.221 & 90 & 12.080 & & \\
\hline & Total & 1.249E9 & 99 & & & \\
\hline \multirow[t]{3}{*}{ Individual1GlassP4AREA } & Between groups & $2.949 \mathrm{e} 8$ & 9 & $3.276 \mathrm{E} 7$ & $3.670 \mathrm{E} 6$ & .000 \\
\hline & Within groups & 803.510 & 90 & 8.928 & & \\
\hline & Total & 2.949E8 & 99 & & & \\
\hline
\end{tabular}

methods). Table 4 shows the results for ANOVA applied on readings obtained from one of the participants.

\section{Pore inter-distance}

Center-to-center distance of four pores, in fingerprints obtained from the left thumb, right index, and right thumb, of four individuals taken on two surfaces, over a duration of ten consecutive days was examined.

Table 5 Mean pore center-to-center distance, standard deviation (S. D.), and \% coefficient of variation (\% C.V.) of four pores, taken from fingerprints obtained from the left thumb of four individuals on glass, recorded on ten consecutive days, shows \% C. V. to lie within and/or near acceptable levels (with 5\% confidence level in analytical work), thereby demonstrating the reliability and reproducibility of pore inter-distance for matching fingerprints

\begin{tabular}{llllll}
\hline Center-to-center length & $\begin{array}{l}\text { Mean pore-to-pore } \\
\text { distance taken from } \\
\text { centre }(\boldsymbol{\mu m})\end{array}$ & S. D. & \% C. V. \\
\hline Individual 1 & Pore1-Pore2 & 340.95 & 8.91 & 2.61 \\
& Pore2-Pore3 & 252.37 & 11.13 & 4.41 \\
& Pore3-Pore4 & 209.59 & 14.82 & 7.07 \\
Individual 2 & Pore1-Pore2 & 389.86 & 18.38 & 4.71 \\
& Pore2-Pore3 & 404.85 & 12.56 & 3.10 \\
& Pore3-Pore4 & 299.80 & 18.79 & 6.27 \\
Individual 3 & Pore1-Pore2 & 440.92 & 23.51 & 5.33 \\
& Pore2-Pore3 & 430.40 & 14.12 & 3.28 \\
& Pore3-Pore4 & 373.00 & 16.67 & 4.47 \\
Individual 4 & Pore1-Pore2 & 395.33 & 16.17 & 4.09 \\
& Pore2-Pore3 & 382.09 & 16.84 & 4.40 \\
& Pore3-Pore4 & 236.61 & 20.80 & 8.79 \\
\hline
\end{tabular}

Pore inter-distance was found to be within and/or near acceptable levels (with 5\% confidence level in analytical work), thereby demonstrating the reliability and reproducibility of pore-to-pore distance for matching fingerprints (Tables 5, 6, and 7).

Additionally, pore inter-distance was found to be significant $(p<0.001)$ on ten consecutive days, for all four participants, on both the surfaces. Table 8 shows the

Table 6 Mean pore center-to-center distance, standard deviation (S. D.), and \% coefficient of variation (\% C.V.) of four pores, taken from fingerprints obtained from the right index finger of four individuals on sticky side of adhesive tape (using method described in (ii)), recorded on ten consecutive days, shows \% C. V. to lie within and/or near the normal acceptable level (with 5\% confidence levels in analytical work), thereby demonstrating the reliability and reproducibility of pore interdistance for matching fingerprints

\begin{tabular}{rllll}
\hline Center-to-center length & $\begin{array}{l}\text { Mean pore-to-pore } \\
\text { distance taken from } \\
\text { center }(\boldsymbol{\mu m})\end{array}$ & S. D. & \% C. V. \\
\hline Individual 1 & Pore1-Pore2 & 366.29 & & \\
& Pore2-Pore3 & 347.14 & 20.37 & 5.56 \\
& Pore3-Pore4 & 411.69 & 20.55 & 5.92 \\
Individual 2 & Pore1-Pore2 & 284.38 & 12.88 & 3.12 \\
& Pore2-Pore3 & 287.05 & 6.79 & 2.39 \\
& Pore3-Pore4 & 229.19 & 13.03 & 4.54 \\
Individual 3 & Pore1-Pore2 & 299.48 & 17.07 & 7.45 \\
& Pore2-Pore3 & 396.53 & 13.16 & 4.40 \\
& Pore3-Pore4 & 286.18 & 19.58 & 4.94 \\
Individual 4 & Pore1-Pore2 & 254.91 & 23.39 & 8.17 \\
& Pore2-Pore3 & 348.89 & 18.10 & 7.10 \\
& Pore3-Pore4 & 525.73 & 19.04 & 5.46 \\
& & 24.74 & 4.71 \\
\hline
\end{tabular}


Table 7 Mean pore center-to-center distance, standard deviation (S. D.), and \% coefficient of variation (\% C.V.) of four pores, taken from fingerprints obtained from the right thumb of four individuals on sticky side of adhesive tape (using method described in (iii)), recorded on ten consecutive days, show \% C. $\checkmark$. to be within and/or near the normal acceptable level (with 5\% confidence levels in analytical work), thereby demonstrating the reliability and reproducibility of pore inter-distance for matching fingerprints

\begin{tabular}{llllll}
\hline Center-to-center length & $\begin{array}{l}\text { Mean pore-to-pore } \\
\text { distance taken from } \\
\text { center }(\boldsymbol{\mu m})\end{array}$ & S. D. & $\%$ C. V. \\
\hline Individual 1 & Pore1-Pore2 & 408.94 & & \\
& Pore2-Pore3 & 288.47 & 16.72 & 4.09 \\
& Pore3-Pore4 & 294.29 & 12.86 & 4.46 \\
Individual 2 & Pore1-Pore2 & 375.19 & 11.86 & 4.03 \\
& Pore2-Pore3 & 436.15 & 18.92 & 5.04 \\
& Pore3-Pore4 & 380.87 & 15.60 & 3.58 \\
Individual 3 3 & Pore1-Pore2 & 553.21 & 9.69 & 2.54 \\
& Pore2-Pore3 & 440.14 & 17.85 & 3.23 \\
& Pore3-Pore4 & 653.77 & 19.90 & 4.52 \\
Individual 4 & Pore1-Pore2 & 370.53 & 17.17 & 2.63 \\
& Pore2-Pore3 & 515.78 & 17.29 & 4.67 \\
& Pore3-Pore4 & 484.45 & 17.41 & 3.38 \\
& & & 20.94 & 4.32 \\
\hline
\end{tabular}

results for ANOVA applied on readings obtained from one of the participants.

\section{Angle}

The angle between center-to-center lengths was considered in the present study. Tables 9, 10, and 11 depict the

Table 8 Results obtained using ANOVA for fingerprints obtained from the left thumb of individual 1 on glass with "center-tocenter length" as the "dependent variable"

\begin{tabular}{|c|c|c|c|c|c|c|}
\hline \multicolumn{7}{|l|}{ ANOVA } \\
\hline & & $\begin{array}{l}\text { Sum of } \\
\text { squares }\end{array}$ & Df & Mean square & $F$ & Sig. \\
\hline \multirow{3}{*}{$\begin{array}{l}\text { Individual- } \\
\text { 1GlassP1to- } \\
\text { P2LENGTH }\end{array}$} & $\begin{array}{l}\text { Between } \\
\text { groups }\end{array}$ & 7147.311 & 9 & 794.146 & 5.030E6 & .000 \\
\hline & $\begin{array}{l}\text { Within } \\
\text { groups }\end{array}$ & .014 & 90 & .000 & & \\
\hline & Total & 7147.325 & 99 & & & \\
\hline \multirow{3}{*}{$\begin{array}{l}\text { Individual- } \\
\text { 1GlassP2to- } \\
\text { P3LENGTH }\end{array}$} & $\begin{array}{l}\text { Between } \\
\text { groups }\end{array}$ & $11,152.109$ & 9 & 1239.123 & 6.914E6 & .000 \\
\hline & $\begin{array}{l}\text { Within } \\
\text { groups }\end{array}$ & .016 & 90 & .000 & & \\
\hline & Total & $11,152.125$ & 99 & & & \\
\hline \multirow{3}{*}{$\begin{array}{l}\text { Individual- } \\
\text { 1GlassP3to- } \\
\text { P4LENGTH }\end{array}$} & $\begin{array}{l}\text { Between } \\
\text { groups }\end{array}$ & $19,756.760$ & 9 & 2195.196 & $1.220 \mathrm{E} 4$ & .000 \\
\hline & $\begin{array}{l}\text { Within } \\
\text { groups }\end{array}$ & 16.192 & 90 & .180 & & \\
\hline & Total & $19,772.952$ & 99 & & & \\
\hline
\end{tabular}

Table 9 Mean angle between center-to-center lengths, standard deviation (S. D.), and \% coefficient of variation (\% C.V.) of four pores, taken from fingerprints obtained from the left thumb of four individuals on glass, recorded on ten consecutive days, show \% C. V. to be within the normal acceptable level (with 5\% confidence level in analytical work)

\begin{tabular}{lllll}
\hline $\begin{array}{l}\text { Angle between center-to- } \\
\text { center lengths }\end{array}$ & Mean angle $\left(^{\mathbf{0}}\right)$ & S. D. & \% C. V. \\
\hline Individual 1 & Angle 1 & 164.35 & 6.47 & 3.93 \\
& Angle 2 & 188.38 & 7.42 & 3.94 \\
Individual 2 & Angle 1 & 196.18 & 2.11 & 1.07 \\
& Angle 2 & 192.19 & 4.03 & 2.10 \\
Individual 3 & Angle 1 & 193.03 & 6.27 & 3.25 \\
& Angle 2 & 189.26 & 6.77 & 3.58 \\
Individual 4 & Angle 1 & 146.83 & 5.63 & 3.84 \\
& Angle 2 & 152.68 & 4.89 & 3.20 \\
\hline
\end{tabular}

mean angle between center-to-center lengths, standard deviation (S. D.), and \% coefficient of variation (\% C.V.) of four pores, in fingerprints obtained from the left thumb, right index finger, and right thumb of four individuals taken on two surfaces over a time period of ten consecutive days. \% C. V. was found to be within the normal acceptable level (with 5\% confidence level in analytical work).

Furthermore, the angle was found to be significant $(p<0.001)$ on ten consecutive days, for all four participants, on both the surfaces. Table 12 shows the results for ANOVA applied on readings obtained from one of the participants.

Table 10 Mean angle between center-to-center lengths, standard deviation (S. D.), and \% coefficient of variation (\% C.V.) of four pores, taken from fingerprints obtained from the right index finger of four individuals on sticky side of adhesive tape (using method described in (ii)), recorded on ten consecutive days, show \% C. V. to be within the normal acceptable level (with 5\% confidence level in analytical work)

\begin{tabular}{lllll}
\hline $\begin{array}{l}\text { Angle between center-to- } \\
\text { center lengths }\end{array}$ & Mean angle $\left.\mathbf{(}^{\mathbf{0}}\right)$ & S. D. & \% C. V. \\
\hline Individual 1 & Angle 1 & 168.66 & 4.27 & 2.53 \\
& Angle 2 & 167.82 & 1.97 & 1.18 \\
\multirow{2}{*}{ Individual 2 } & Angle 1 & 191.67 & 7.24 & 3.78 \\
& Angle 2 & 175.63 & 3.79 & 2.16 \\
\multirow{2}{*}{ Individual 3 } & Angle 1 & 185.19 & 3.96 & 2.14 \\
& Angle 2 & 152.76 & 3.58 & 2.34 \\
Individual 4 & Angle 1 & 195.40 & 4.61 & 2.36 \\
& Angle 2 & 182.23 & 5.26 & 2.88 \\
\hline
\end{tabular}


Table 11 Mean angle between center-to-center lengths, standard deviation (S. D.), and \% coefficient of variation (\% C.V.) of four pores, taken from fingerprints obtained from the right thumb of four individuals on sticky side of adhesive tape (using method described in (iii)), recorded on ten consecutive days, show \% C. V. to be within the normal acceptable level (with 5\% confidence level in analytical work)

\begin{tabular}{lllll}
\hline $\begin{array}{l}\text { Angle between center-to- } \\
\text { center lengths }\end{array}$ & Mean angle $\mathbf{(}^{\mathbf{}}$ ) & S. D. & \% C. V. \\
\hline Individual 1 & Angle 1 & 181.28 & 7.18 & 3.96 \\
& Angle 2 & 184.37 & 3.69 & 2.00 \\
Individual 2 & Angle 1 & 187.88 & 1.73 & 0.92 \\
& Angle 2 & 126.05 & 3.47 & 2.75 \\
Individual 3 & Angle 1 & 165.89 & 7.99 & 4.82 \\
& Angle 2 & 188.42 & 7.61 & 4.04 \\
\multirow{2}{*}{ Individual 4 } & Angle 1 & 170.99 & 5.20 & 3.04 \\
& Angle 2 & 178.99 & 5.00 & 2.80 \\
\hline
\end{tabular}

\section{Discussion}

Poroscopy as a tool for personal identification is accepted in theory but ignored in practice (Ashbaugh 1999). The absence of set guidelines and clear consensus on the classification, reproducibility, and individual value of sweat pores, among practitioners, along with limited research work on the various aspects of sweat pores restricts their use as an efficient means of identification (Anthonioz et al. 2008).

The present research work aimed at assessing the reproducibility and reliability of pore area, inter-distance, and angle for matching fingerprints (Fig. 3). The pore area was found to be significantly variable in fingerprints recorded on ten consecutive days on both the surfaces (glass and sticky side of adhesive tape). The results obtained are similar to that of previous studies wherein the pore area was found to be non-reproducible (Faulds 1913) in inked fingerprints (Gupta et al. 2007), latent prints (developed using ninhydrin and cyanoacrylate fuming) (Gupta et al. 2008), and direct microscopic and livescan images at 500ppi (Gupta and Sutton 2010).
The use of pore-to-pore distance for individualizing fingerprints has been effectively suggested by many studies (Anthonioz et al. 2011; Ashbaugh 1999; Monson et al. 2019; Oklevski 2011; Oktem et al. 2015; Parsons et al. 2008; WooáLee and JunáPark 2015). However, as far as the authors are aware, no study has demonstrated the same using empirical data. The present study examined pore inter-distance (taken from center of one pore to the centre of the adjacent pore) in fingerprints obtained from four individuals on two surfaces (glass and sticky side of adhesive tape) for a period of ten consecutive days and found pore inter-distance to be a reproducible parameter $(\% \mathrm{C}$. V. was within and/or near the normal acceptable level, with $5 \%$ confidence level in analytical work). Moreover, the angle (between pores) was also found to be reproducible, thereby strengthening the possibility of matching fingerprints using sweat pores.

\section{Conclusions}

The current study was undertaken to highlight the reproducibility and reliability of sweat pore inter-distance and angle in inked fingerprints so that the results obtained can encourage further research on this highly neglected field of forensic science.

The results indicate that pore inter-distance and angle are reproducible parameters and can be utilized for fingerprint matching. Additionally, out of the two surfaces namely, glass and sticky side of adhesive tape, better quality of pores was visible in the case of fingerprints recorded on the sticky side of adhesive tape using method (iii) wherein the sticky side of adhesive tape was pressed against the inked thumb of the participant.

This study envisages to standardize a method for obtaining inked specimen fingerprints on the sticky side of adhesive tape so that, if need be, pore details can be utilized for comparison purpose. The authors suggest matching the questioned fingerprint with the specimen print on the basis of ridge characteristics first. On

Table 12 Results obtained using ANOVA for fingerprints obtained from the left thumb of individual 1 on glass with "angle" as the "dependent variable"

\begin{tabular}{|c|c|c|c|c|c|c|}
\hline \multicolumn{7}{|l|}{ ANOVA } \\
\hline & & Sum of squares & df & Mean square & $F$ & Sig. \\
\hline \multirow[t]{3}{*}{ Individual1GlassANGLE1 } & Between groups & 3761.836 & 9 & 417.982 & 3.906E6 & .000 \\
\hline & Within groups & .010 & 90 & .000 & & \\
\hline & Total & 3761.846 & 99 & & & \\
\hline \multirow[t]{3}{*}{ Individual1GlassANGLE2 } & Between groups & 4954.066 & 9 & 550.452 & 3.305E6 & .000 \\
\hline & Within groups & .015 & 90 & .000 & & \\
\hline & Total & 4954.081 & 99 & & & \\
\hline
\end{tabular}




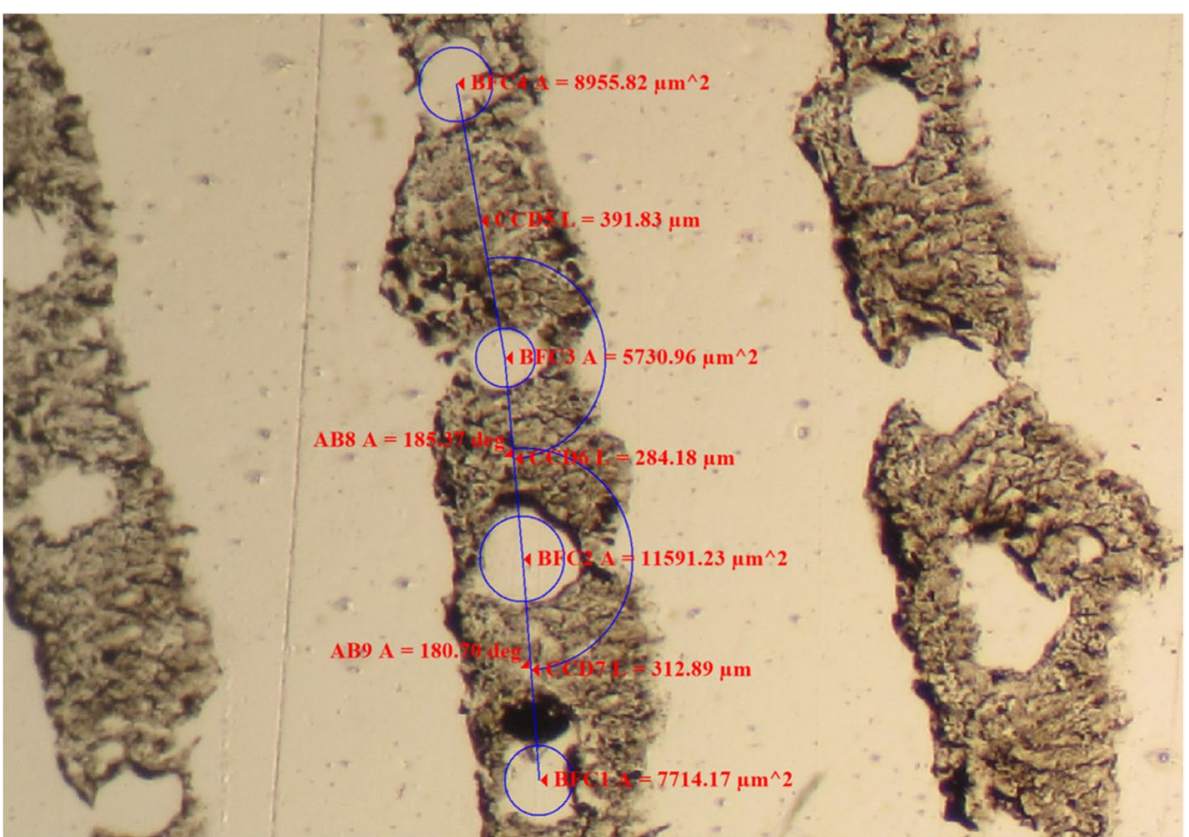

Fig. 3 Fingerprint pore area, pore center-to-center distance, and angle analyzed using Image Pro ${ }^{\circledR}$ Software

occasions when sufficient number of characteristics are not available for comparison, sweat pores should be employed in the forensic casework. Sweat pores should always be used in conjunction with ridge characteristics. The authors by no means suggest ignoring minutiae and focusing on sweat pores alone.

\section{Abbreviations}

ACE-V: Analysis-Comparison-Evaluation and Verification; ANOVA: One-way analysis of variation; S.D.: Standard deviation; SOC: Scene of crime; SPSS: Statistical Product and Service Solutions.

\section{Acknowledgements}

The authors would like to thank University Grants Commission - Junior Research Fellowship (UGC-Ref. No.: 3556/(NET-JULY 2018) for funding this research work. We are also thankful to all the participants.

\section{Authors' contributions}

JK contributed to the concept of the paper, investigation, methodology, analysis, and writing — original draft; MD contributed to the concept of the paper, writing — review and editing, and critical evaluation. Both the authors read and approved the final manuscript.

\section{Funding}

UGC-JRF (UGC-Ref. No.: 3556/(NET-JULY 2018)

Availability of data and materials

All data is available with the authors.

\section{Declarations}

\section{Ethics approval and consent to participate}

Ethical clearance was obtained from the Ethical Committee of Department of Anthropology, University of Delhi, India. Informed written consent was obtained from all participants prior to collecting their fingerprint samples (Ref. No./Anth./2018/2880/28-12-18)

\section{Consent for publication}

Not applicable

\section{Competing interests}

The authors declare that they have no competing interests.

Received: 7 July 2021 Accepted: 12 January 2022

Published online: 31 January 2022

\section{References}

Anthonioz A, Egli N, Champod C, Neumann C, Puch-Solis R, Bromage-Griffiths A (2008) Level 3 details and their role in fingerprint identification: a survey among practitioners. J Forensic Identification 58(5):562-589

Anthonioz A, Egli N, Champod C, Neumann C, Puch-Solis R, Bromage-Griffiths A (2011) Investigation of the reproducibility of third-level characteristics. J Forensic Identification 61(2):171

Ashbaugh DR (1999) Quantitative-qualitative friction ridge analysis: an introduction to basic and advanced ridgeology. CRC Press, Boca Raton

Ashbaugh DR, Houck MM (2005) Fingerprints and admissibility: friction ridges and science. Can J Police Secur Serv 3(2):69-69

Bindra B, Jasuja O, Singla A (2000) Poroscopy: a method of personal identification revisited. Anil Aggrawal's Internet J Forensic Med Toxicol 1(1)

Cai L, Xia M-C, Wang Z, Zhao Y-B, Li Z, Zhang S, Zhang X (2017) Chemical visualization of sweat pores in fingerprints using GO-enhanced TOF-SIMS. Anal Chem 89(16):8372-8376

Faulds H (1913) Poroscopy: the scrutiny of sweat-pores for identification. Nature 91(2286):635-636

Gupta A, Buckley K, Sutton R (2008) Latent fingermark pore area reproducibility. Forensic Sci Int 179(2-3):172-175

Gupta A, Buckley KA, Sutton R (2007) The effect of substrate on the reproducibility of inked fingerprint pore dimensions examined using photomicrography 
Gupta A, Sutton R (2010) Pore sub-features reproducibility in direct microscopic and livescan images - their reliability in personal identification. J Forensic Sci 55(4):970-975

Jain AK, Chen Y, Demirkus M (2006) Pores and ridges: high-resolution fingerprint matching using level 3 features. IEEE Trans Pattern Anal Mach Intell 29(1):15-27

Kapoor N, Badiye A (2015) Sex differences in the thumbprint ridge density in a central Indian population. Egypt J Forensic Sci 5(1):23-29

Kryszczuk, K. M., Morier, P., \& Drygajlo, A. (2004). Study of the distinctiveness of level 2 and level 3 features in fragmentary fingerprint comparison. Paper presented at the International Workshop on Biometric Authentication.

Labati RD, Genovese A, Muñoz E, Piuri V, Scotti F (2018) A novel pore extraction method for heterogeneous fingerprint images using convolutional neural networks. Pattern Recogn Lett 113:58-66

Lee J, Pyo M, Lee S-H, Kim J, Ra M, Kim W-Y et al (2014) Hydrochromic conjugated polymers for human sweat pore mapping. Nat Commun 5(1):1-10

Liu F, Zhao Y, Liu G, Shen L (2020) Fingerprint pore matching using deep features. Pattern Recogn 102:107208

Maltoni D, Maio D, Jain AK, Prabhakar S (2009) Handbook of fingerprint recognition. Springer Science \& Business Media, Berlin

Monson KL, Roberts MA, Knorr KB, Ali S, Meagher SB, Biggs K et al (2019) The permanence of friction ridge skin and persistence of friction ridge skin and impressions: a comprehensive review and new results. Forensic Sci Int 297:111-131

Nagesh K, Bathwal S, Ashoka B (2011) A preliminary study of pores on epidermal ridges: are there any sex differences and age related changes? J Forensic Legal Med 18(7):302-305

Oklevski S (2011) Poroscopy: qualitative and quantitative analysis of the 2 nd and 3 rd level detail and their relation. Fingerprint Whorld 37(145):170-181

Oktem H, Kurkcuoglu A, Pelin IC, Yazici AC, Aktaş G, Altunay F (2015) Sex differences in fingerprint ridge density in a Turkish young adult population: a sample of Baskent University. J Forensic Legal Med 32:34-38

Pankanti S, Prabhakar S, Jain AK (2002) On the individuality of fingerprints. IEEE Trans Pattern Anal Mach Intell 24(8):1010-1025

Park D-H, Park BJ, Kim J-M (2016) Hydrochromic approaches to mapping human sweat pores. Acc Chem Res 49(6):1211-1222

Parsons NR, Smith J, Thönnes E, Wang L, Wilson R (2008) Rotationally invariant statistics for examining the evidence from the pores in fingerprints. Law Probability Risk 7(1):1-14

Preethi DS, Nithin MD, Manjunatha B, Balaraj BM (2012) Study of poroscopy among South Indian population. J Forensic Sci 57(2):449-452

Stosz, J. D., \& Alyea, L. A. (1994). Automated system for fingerprint authentication using pores and ridge structure. Paper presented at the Automatic systems for the identification and inspection of humans.

Thakar MK, Sharma T (2016) Digital grid method for fingerprint identification and objective report writing. Egypt J Forensic Sci 6(2):194-201

Vij K (2001) Textbook of forensic medicine, principles and practice, vol 1. BI Churchill Livingstone, New Delhi, p 740

WooáLee C, JunáPark B (2015) Sweat pore mapping using a fluoresceinpolymer composite film for fingerprint analysis. Chem Commun 51(15):3177-3180

Zhao Q, Feng J, Jain AK (2010a) Latent fingerprint matching: utility of level 3 features. MSU Techical Rep 8:1-30

Zhao Q, Zhang D, Zhang L, Luo N (2010b) High resolution partial fingerprint alignment using pore-valley descriptors. Pattern Recogn 43(3):1050-1061

\section{Publisher's Note}

Springer Nature remains neutral with regard to jurisdictional claims in published maps and institutional affiliations. 